\title{
A Dog with Myelodysplastic Syndrome: Chronic Myelomonocytic Leukemia
}

\author{
Hiroko HIRAOKA ${ }^{1)}$, Masaharu HISASUE ${ }^{2}$, Naho NAGASHIMA ${ }^{2}$, Takako MIYAMA ${ }^{1)}$, Takashi TANIMOTO ${ }^{1)}$, \\ Malaika WATANABE ${ }^{1)}$, Kazuhito ITAMOTO ${ }^{3)}$, Takuya MIZUNO ${ }^{1)}$, Hisashi INOKUMA ${ }^{4)}$ and Masaru OKUDA ${ }^{1) *}$ \\ ${ }^{1)}$ Laboratories of Veterinary Internal Medicine and ${ }^{3)}$ Veterinary Surgery, Faculty of Agriculture, Yamaguchi University, 1677-1 Yoshida, \\ Yamaguchi 753-8515, 2) Laboratory of Veterinary Internal Medicine II, School of Veterinary Medicine, Azabu University, 1-17-71 \\ Fuchinobe, Sagamihara, Kanagawa 228-8501 and ${ }^{4)}$ Department of Veterinary Medicine, Obihiro University of Agriculture and \\ Veterinary Medicine, Inada, Obihiro 080-8555, Japan
}

(Received 4 April 2006/Accepted 22 February 2007)

ABSTRACT. An eleven-year-old female pug was referred to Yamaguchi University Animal Hospital for evaluation of anemia and thrombocytopenia. The cytological examination of the peripheral blood showed some giant monocytic lineage blast cells. A few granulocytes and platelets had dysplastic features. On day 7, in addition to increasing the monocytic lineage cells, the dysplastic features of the blood had also increased compared to the initial examination. We performed bone marrow aspiration upon her death. The bone marrow revealed dysplastic features in all three hematopoietic cell lines, and an increase in the monocytic cell line. Based on the features of the bone marrow and the peripheral blood, this case was confirmed to be myelodysplastic syndrome — Chronic myelomonocytic leukaemia (MDS-CMML).

KEY WORDS: dysplastic features, MDSs, monocytosis.

J. Vet. Med. Sci. 69(6): 665-668, 2007

Myelodysplastic syndromes (MDSs) are a heterogeneous group of acquired hematological disorders that are characterized by prominent dysplastic features in multiple cell lines in the blood and bone marrow $[2,5,6,8,10]$. MDSs are divided into two categories-primary and secondary [13]. The initiating cause of primary MDSs in dogs has not yet been identified $[6,7]$, but it is thought to be due to genetic alterations in hematopoietic stem cells $[2,12,14]$. Chronic myelomonocytic leukaemia (CMML) has been defined as one of the types of MDSs in the French-American-British (FAB) system of classification [1]; however, no case reports have been documented in dogs with MDS-CMML in our best knowledge. This case report describes the clinicopathological features of a dog with suspected MDS-CMML.

An eleven-year-old female pug was referred to Yamaguchi University Animal Hospital for evaluation of progressive anemia and thrombocytopenia which had not responded to seven days treatment with prednisolone $(3 \mathrm{mg} /$ $\mathrm{kg}$, once daily). Upon physical examination, fever $\left(40^{\circ} \mathrm{C}\right)$, pale mucous membranes and mild dyspnea were identified (Day 1). Mild bronchitis and splenomegaly were confirmed by radiological examination. The hemogram indicated a normocytic (mean corpuscular volume, $69.5 \mathrm{fl}$ ), normochromic (mean corpuscular hemoglobin concentration, $32.7 \mathrm{~g} /$ $\mathrm{d} l$ ), non-regenerative anemia (hematocrit, $16 \%$, reticulocyte production index, 0.15$)$ and thrombocytopenia $\left(48 \times 10^{3 /}\right.$ $\mu l)$. The leukocyte count was within the normal range $(14,949 / \mu l$, Table 1$)$. The cytological examination of the peripheral blood showed a left shift neutrophilia, some giant monocytic lineage blast cells and a small number of myeloid blast cells. These blast cells were distinguished by

\footnotetext{
* CoRRespondence to: OKUdA, M., Laboratory of Veterinary Internal Medicine, Faculty of Agriculture, Yamaguchi University, Yamaguchi 753-8515, Japan.
}

peroxidase and alpha-naphthyl butyrate esterase stain. A few granulocytes had dysplastic features, including bizarre nuclear shape, and asynchronous maturation of nuclei and cytoplasm. Large platelets were also seen. Differential diagnoses for this case included MDSs and acute myeloid leukemia (AML). Therefore, we suggested bone marrow aspiration to make a final diagnosis. However, the owner did not consent to perform the bone marrow aspiration. Consequently, we started treatment with oral cyclosporine

Table 1. Results of hematological examination at day 1 and day 7

\begin{tabular}{lccc}
\hline Complete blood count & Day 1 & Day 7 & Reference range* \\
\hline $\left.\mathrm{RBC}^{\mathrm{a}}\right)\left(\times 10^{6} / \mu l\right)$ & 2.3 & 2.4 & $5.5-8.5$ \\
$\mathrm{Hb}^{\mathrm{b})}(\mathrm{g} / \mathrm{d} l)$ & 5.3 & 5.5 & $12.0-18.0$ \\
$\mathrm{Hematocrit}^{(\%)}$ & 16 & 15 & $37-55$ \\
$\mathrm{MCV}^{\mathrm{c})}(\mathrm{fl})$ & 69.5 & 67.9 & $60-77$ \\
$\mathrm{MCHC}^{\mathrm{d})}(\mathrm{g} / \mathrm{d} l)$ & 32.7 & 34.2 & $32-36$ \\
Platelet $\left(\times 10^{3} / \mu l\right)$ & 48 & 4 & $200-500$ \\
$\mathrm{WBC}(/ \mu l)$ & 14,949 & 13,450 & $6,000-17,000$ \\
Myelocyte & 151 & 145 & \\
Metamyelocyte & 2,265 & 290 & \\
Band Neutrophil & 3,473 & 1,160 & $0-300$ \\
Segmented Neutrophil & 7,701 & 4,785 & $3,000-11,500$ \\
Eosinophil & 0 & 0 & $100-1,250$ \\
Basophil & 0 & 0 & \\
Lymphocyte & 604 & 725 & $1,000-4,800$ \\
Monoblast & 151 & 145 & \\
Promonocyte & 302 & 2,175 & \\
Monocyte & 302 & 4,025 & $150-1,350$ \\
Nucleated RBC $(/ \mu l)$ & 151 & 870 & \\
\hline
\end{tabular}

a) RBC: red blood cell.

b) $\mathrm{Hb}$ : hemoglobin.

c) MCV: mean corpuscular volume.

d) MCHC: mean corpuscular hemoglobin concentration.

e) WBC: white blood cell.

* Schalm's Veterinary Hematology 5th Ed. 


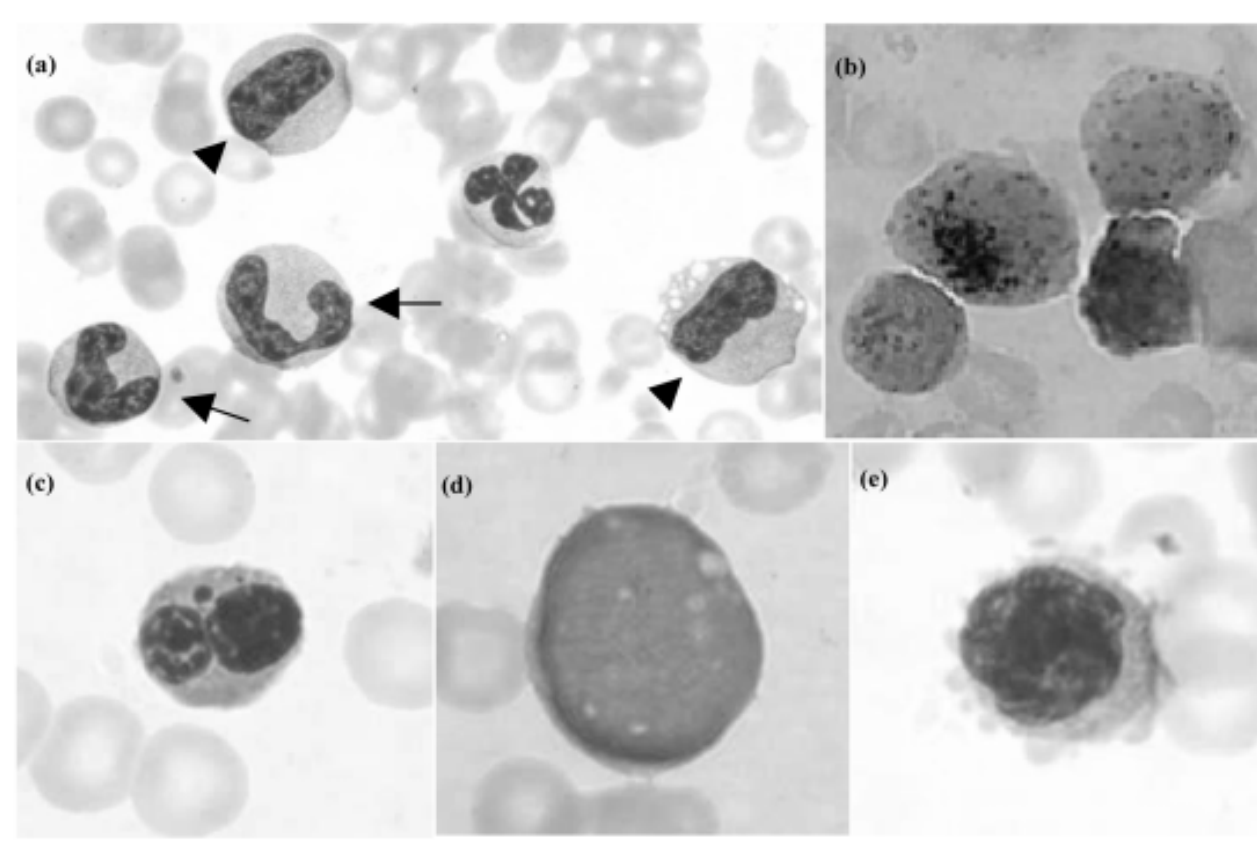

Fig. 1. Photomicrographs of the peripheral blood on day 7. The numbers of monocytic lineage cells were increased than those of day 1, and dysplastic features are obtained in all three cell lines. (a) Promonocytes (arrowheads) and monocytes (arrows), (b) positive staining for alpha-naphthyl butyrate esterase, (c) lobulated rubricytes, (d) large palatets and (e) micromegakaryocytes.

(7 $\mathrm{mg} / \mathrm{kg}$, once daily) and blood transfusion as supportive therapy. However, on day 7, the dog's condition worsened and the red blood cell and platelet counts decreased in spite of a blood transfusion administered six days earlier (hematocrit, $15 \%$ and platelet counts, $4 \times 10^{3} / \mu l$ ). The leukocyte count slightly decreased, but it was still within the normal range $(13,450 / \mu l$, Table 1$)$. In the peripheral blood, the number of promonocytes and monocytes were clearly increased (Table $1 \&$ Fig. 1a). These monocytic lineage cells stained positive for alpha-naphthyl butyrate esterase (Fig. 1b) with sodium fluoride inhibition (data not shown). The dysplastic features of the blood-lobulated rubricytes (Fig. 1c), granulocytes with pseudo-Pelger-Huët anomaly and hypersegmentation, large platelets (Fig. 1d) and micromegakaryocytes (Fig. 1e) — had increased compared to those observed at the initial examination. The patient was administered supportive care, including blood transfusion, but she died on the same day. The cause of her death was not determined because we could not do autopsy. Immediately, upon her death, we performed bone marrow aspiration with the owner's consent. Examination of the bone marrow revealed normocellularity and the ratio of myeloid cells relative to erythroid cells (M: E) was 1.9:1 (Table 2 \& Fig. 2a). The ratio of blast cells to all nucleated cells (ANC) was $8.5 \%$. There were few mature leukocytes, and an increase in the monocytic lineage cells was observed which accounted for $13.1 \%$ of ANC in the bone marrow (Table $2 \&$ Fig. $2 b$ ). The most of mature monocytic lineage cells stained positive for alpha-naphtyrate butyrate esterase with sodium fluoride inhibition. Furthermore, there were certain dysplastic fea-
Table 2. Myelogram on day 7

\begin{tabular}{|c|c|}
\hline Cell type & Percentage (\%) \\
\hline Rubriblast & 0.2 \\
\hline Basophilic rubricyte & 0.0 \\
\hline Polychromatic rubricyte & 16.9 \\
\hline Metarubricyte & 10.4 \\
\hline Myeloblast & 5.7 \\
\hline Promyelocyte & 0.0 \\
\hline Myelocyte & 22.4 \\
\hline Metamyelocyte & 14.4 \\
\hline Band neutrophil & 7.0 \\
\hline Segmented neutrophil & 1.5 \\
\hline Band eosinophil & 2.3 \\
\hline Segmented eosinophil & 0.0 \\
\hline Band basophil & 0.0 \\
\hline Segmented basophil & 0.0 \\
\hline Monoblast & 2.1 \\
\hline Promonocyte & 0.2 \\
\hline Monocyte & 10.8 \\
\hline Lymphoblast & 0.0 \\
\hline Lymphocyte & 5.3 \\
\hline Megakaryoblast & 0.0 \\
\hline Megakaryocyte & 0.8 \\
\hline M:E ratio ${ }^{a}$ & 1.9 \\
\hline \multicolumn{2}{|l|}{ Blast ratio } \\
\hline $\mathrm{ANC}^{\mathrm{b})}$ & 8.5 \\
\hline $\mathrm{NEC}^{\mathrm{c})}$ & 11.7 \\
\hline
\end{tabular}

a) M:E ratio: myeloid cells relative to erythroid cells ratio. b) ANC: all nucleated cells, c) NEC: non-erythroid cells. 


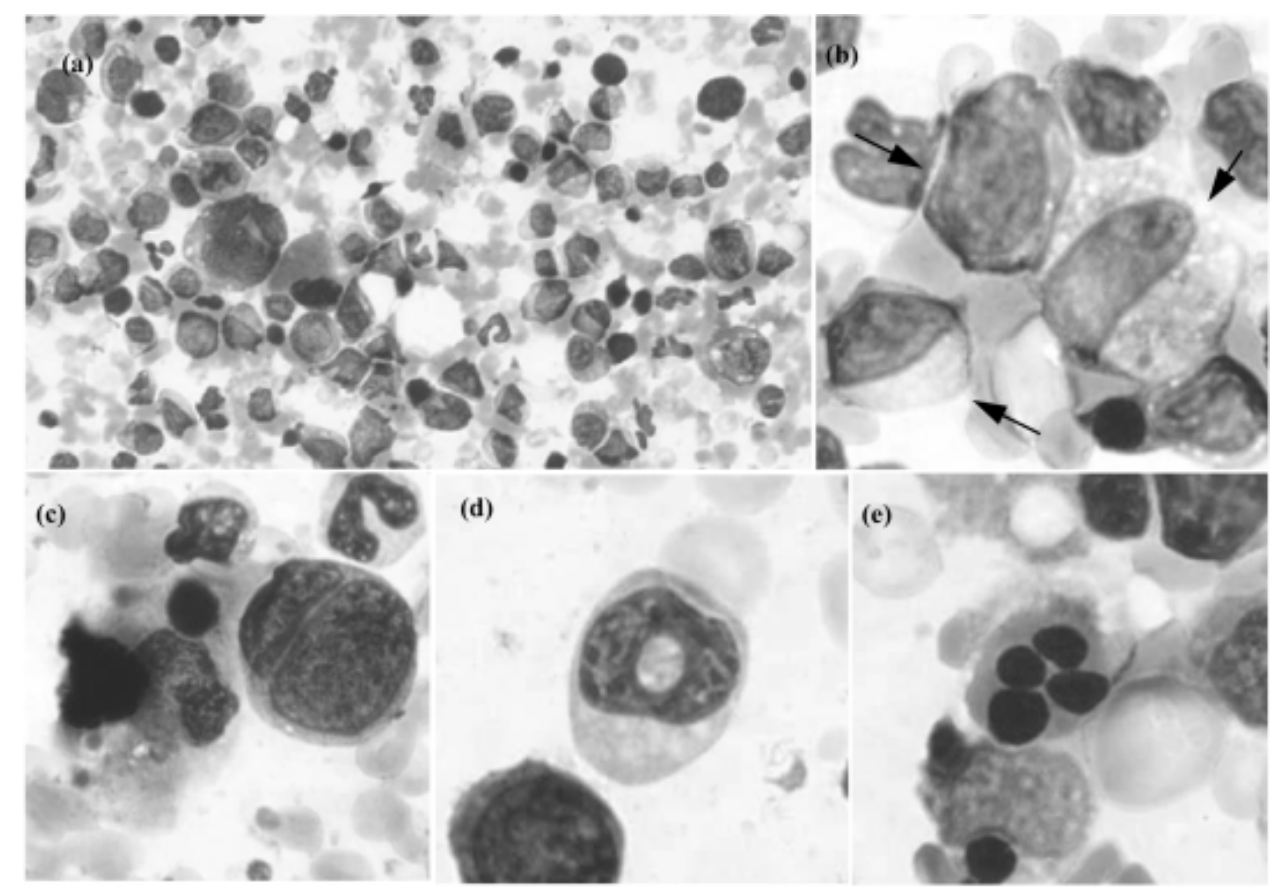

Fig. 2. Photomicrographs of the bone marrow aspirate on day 7. (a) Low magnification of the marrow smear, (b) monocytic lineage cells (arrows), (c) macrophage phagocytosis and unequal division of blast cell, (d) doughnut-shaped neutrophil precursors and (e) rubricytes with multi-nuclei.

tures in all three hematopoietic cell lines. These dysplastic changes included doughnut-shaped neutrophil precursors (Fig. 2d), asynchronously maturated rubricytes and rubricytes with multi-nuclei (Fig. 2e), mononuclear megakaryocytes and micromegakaryocytes. Additionally, macrophage phagocytosis was observed (Fig. 2c). Based on the features of the bone marrow and the peripheral blood, this case was confirmed to be MDS-CMML.

CMML is classified in the MDSs category by the FAB Cooperative Group, but it has been excluded from the human MDSs classification of the World Health Organization (WHO) scheme $[2,5,12]$. Recently, the WHO system replaced the initial FAB classification for humans due to its improved prognostic discrimination [5]. In the field of veterinary medicine, however, its use has not been critically evaluated in large number of cases [7,12]. It is also thought that CMML is included in MDSs for its mutilineage dyshematopoiesis and cytopenias, and its high tendency to progress to AML [11]. In this case, in addition to severe erythrocytopenia and thorombocytopenia, the patient had serious dysplastic features in all three cell lines of the blood and bone marrow. Consequently, this case was diagnosed as MDS-CMML based on the FAB system. MDSs are regarded as preleukemic disorders, and some cases that progressed to AML have also been reported in dogs $[3,4,9,14$, 15]. In the present case, the circulating monocytic lineage cells had been increasing; however, at the time of death, blast cells constituted less than $30 \%$ of total marrow cells. Therefore, the condition had not progressed to AML.
In dogs, MDSs tends to progress to AML, and therefore, the prognosis is poor. Although many drugs have been evaluated for the treatment of MDSs an appropriate treatment protocol has not yet been established. More case reports and pilot studies for the treatment are required in the future.

\section{REFERENCES}

1. Bennett, J. M., Catovsky, D., Daniel, M.T., Flandrin, G., Galton, D. A. Gralnick, H. R. and Sultan, C. 1982. Br. J. Haematol. 51: 189-199.

2. Blue, J. T. 2003. Toxicol. Pathol. 31: 44-48.

3. Couto, C. G. and Kallet, A. J. 1984. J. Am. Vet. Med. Assoc. 184: 1389-1392.

4. Fujino, Y., Tezuka, K., Hisasue, M., Ohno, K. and Tsujimoto, H. 2003. Vet. Rec. 153: 25-27.

5. Germing, U., Gattermann, N., Strupp, C., Aivado, M. and Aul, C. 2000. Leuk. Resk. 24: 983-992.

6. Jain, N. C., Blue, J. T., Grindem, C. B., Harvey, J. W., Kociba, G. J., Krehbiel, J. D., Latimer, K. S., Raskin, R. E., Thrall, M. A. and Zinkl, L. G. 1991. Vet. Clin. Pathol. 20: 63-82.

7. Julia, J. T. 2000. pp. 682-686. In: Schalm's Veterinary Hematology. 5th ed. (Feldman, B. F., Zinkl, J. G. and Jain, N. C.), Philadelphia, Lippincott Williams and Wilkins.

8. Kouides, P. A. and Bennett, J. M. 1996. Semin. Hematol. 33: 95-110.

9. Mcmanus, P. M. and Hess, R. S. 1998. Vet. Clin. Pathol. 27: 112-115.

10. Raskin, R. E. 1996. Vet. Clin. North Am. Small Anim. Pract. 26: $1023-1042$.

11. Rosati, S., Anastasi, J. and Vardiman, J. 1996. Semin. Hematol. 
33: 111-126.

12. Weiss, D. J. 2003. Vet. Clin. North Am. Small Anim. Pract. 33: 1317-1334.

13. Weiss, D. J. and Aird, B. 2001. Vet. Clin. Pathol. 30: 67-75.
14. Weiss, D. J. and Smith, S. A. 2000. J. Vet. Intern. Med. 14: 491-494.

15. Weiss, D. J., Raskin, R. and Zerbe, C. 1985. J. Am. Vet. Med. Assoc. 187: 1038-1040. 